\title{
Pneumoretroperitoneum after a STARR Procedure Performed One Year after a Posterior Colporrhaphy: A Case Report and Review of the Literature
}

\author{
Ibrahim Darwich $^{a}$ Badrig Melekian $^{\mathrm{b}}$ Serpil Demirel-Darwich ${ }^{\mathrm{b}}$ Frank Willeke $^{\mathrm{a}}$ \\ ${ }^{a}$ Department of Surgery, St. Marienkrankenhaus, Siegen, Germany; ${ }^{b}$ Department of Gynecology and Obstetrics, \\ St. Marienkrankenhaus, Siegen, Germany
}

\section{Keywords}

Pneumoretroperitoneum · TranstarTM $\cdot$ STARR $\cdot$ Obstructed defecation syndrome

\begin{abstract}
Transanal rectal resection with a stapling instrument (STARR) has been shown to be effective and safe for the treatment of obstructed defecation syndrome (ODS). Nevertheless, the wide range of complications described in the literature necessitates a rigorous patient selection and a tailored approach for the management of complications. We present here a case of pneumoretroperitoneum which occurred after a STARR procedure for ODS was performed nearly a year after previous anterior and posterior colporrhaphy. The diagnostic workup did not reveal a staple-line defect. Laparoscopy did not show any intra-abdominal pathology. The symptoms resolved under oral antibiotics. The patient was discharged on day 10 after admission. Scarring in the rectovaginal septum from a colporrhaphy 1 year earlier might have contributed to a suboptimal staple-line closure during the STARR procedure, leading to a pneumoretroperitoneum. We discuss this complication and provide a brief review of the literature.
\end{abstract}

(c) 2020 S. Karger AG, Basel

\section{Introduction}

The STARR procedure involves the use of a transanally applied stapling instrument for rectal resection to treat obstructed defecation syndrome (ODS). Although well established for this indication [1], major complications such as rectal perforation and even fatal necrotizing pelvic fasciitis have been reported [2-4].

Pneumoperitoneum, or rather pneumoretroperitoneum after a transanal stapling procedure, leaves the clinician with a major uncertainty regarding the management of complications. In this case report, we describe a case of pneumoretroperitoneum after a STARR procedure performed with the Contour ${ }^{\circledR}$ Transtar ${ }^{\mathrm{TM}}$ curved cutter stapler 1 year after a posterior and anterior colporrhaphy. The related literature is discussed in a brief review.

\section{Case Report}

A 70-year-old female patient was referred to our surgical department with a 2-year history of constipation. The evaluation of the patient's history, constipation scores, clinical examination, and diagnostic workup (that included MRI defecography and pelvicography with opacification of the small bowel loops as well as the bladder) indicated ODS due to an anterior rectocele and a rectal intussusception (Fig. 1,2). An enterocele was ruled out. A relevant descent of the perineum was not observed. Colonoscopy did not show any pathology. Five months previously, she had undergone anterior and posterior colporrhaphy in the gynecological department of our institute to treat a second-degree cystocele and a rectocele. Since then, she had noticed a deterioration of her ability to evacuate her rectum and a severe worsening of the sensation of incomplete defecation, having to digitate more frequently und to strain. Conservative measures including laxatives, dietary management, pelvic floor exercises, and biofeedback therapy had not been of much help. The patient refused transanal irrigation therapy or the fitting of a pessary.

A transanal approach to excise the intussusception was decided by the joint pelvic-floor multidisciplinary team (MDT) at our in- 


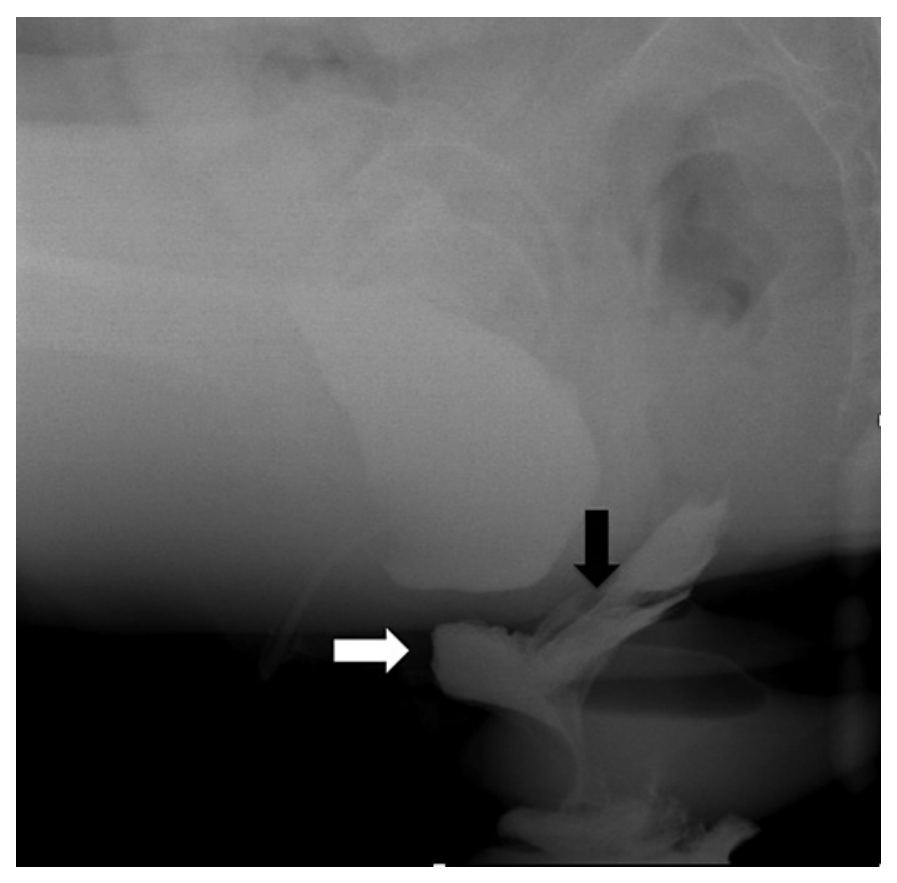

Fig. 1. Pelvicography showing a rectal intussusception (black arrow) and an anterior rectocele (white arrow).

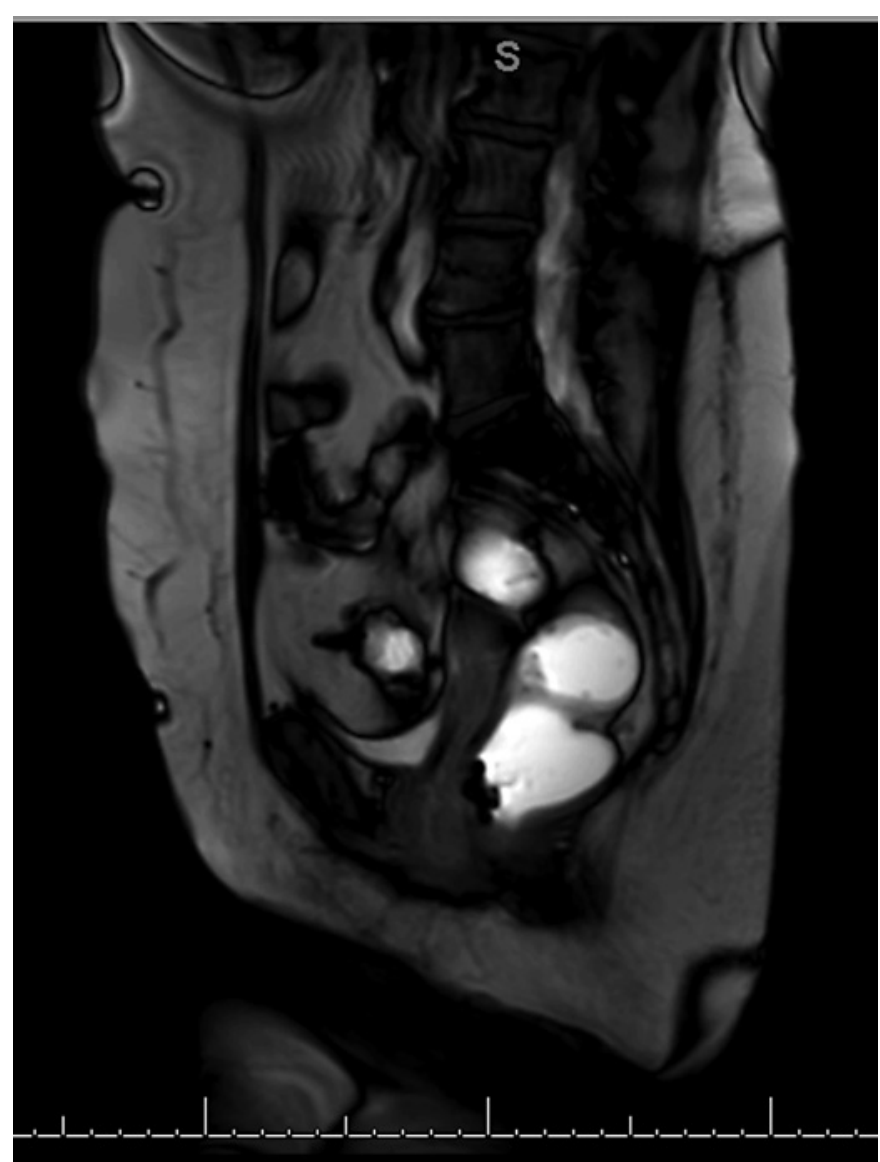

Fig. 2. MRI defecography.

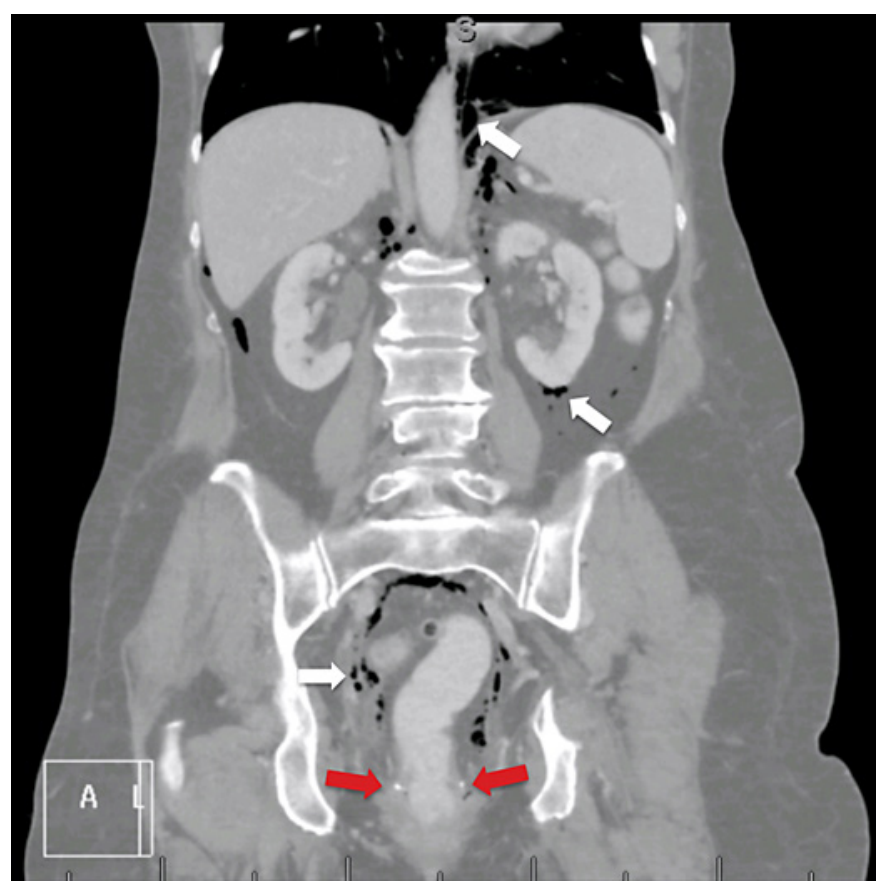

Fig. 3. CT scan showing pneumoretroperitoneum at the level of the mesorectum, kidneys, and also mediastinal (white arrows). The contrast enema revealed no anastomotic leak and hence no evidence of a staple-line dehiscence (red arrows).

stitute. Due to the expected scarring in the region of the rectovaginal septum after the posterior colporrhaphy mentioned above, it was decided to adjourn the procedure until a year had passed since the last operation.

A STARR procedure with a Contour ${ }^{\circledR}$ Transtar $^{\mathrm{TM}}$ curved cutter stapler (Ethicon Endo-Surgery; Cincinnati, OH, USA) was performed without any intraoperative difficulties or complications nearly 1 year after the anterior and posterior colporrhaphy. No staple-line dehiscence or spiraling was encountered intraoperatively. The patient received perioperative intravenous single-dose prophylaxis of $1.5 \mathrm{~g}$ cefuroxime and $0.5 \mathrm{~g}$ metronidazole. On day 1 after surgery, the patient reported lower abdominal pains. Ultrasound showed urinary retention and bladder overflow which was managed with a transurethral catheter. Rectal examination showed an intact staple line. Vaginal examination revealed an intact posterior vaginal wall. On day 2 after surgery, a rise in her white blood cell count (WBC) to $10,300 / \mu \mathrm{L}$, and a C-reactive protein (CRP) level of $161.9 \mathrm{mg} / \mathrm{L}$ was detected. Her body temperature was measured at $38^{\circ} \mathrm{C}$. Rectal examination revealed no pathology. There was no abdominal discomfort or tenderness. Abdominal ultrasound was normal. Oral antibiotics using cefuroxime $0.5 \mathrm{~g}$ b.i.d. and metronidazole $0.4 \mathrm{~g}$ b.i.d. were started and set for a 7-daycourse of therapy. On day 3 , and upon recording a persistent body temperature of $38^{\circ} \mathrm{C}$ and a CRP of $170 \mathrm{mg} / \mathrm{L}$, a CT scan was performed. This revealed pneumoretroperitoneum at the level of the mesorectum, along the aorta and the kidneys, and up to the mediastinum. No anastomotic leak was observed upon transanal injection of water-soluble contrast (Fig. 3). There was no intra-abdominal free air or fluid. We decided to do a diagnostic laparoscopy and inspect the staple line under general anesthesia. The laparoscopy did not reveal any pathologies. A drain was brought into the Douglas pouch. The rectal examination under general anesthesia confirmed an intact staple line with no signs of dehiscence, bleeding, or ischemia. Vaginal examination revealed an intact mucosa. 
Table 1. A short review of publications describing retroperitoneal air following trananal stapling procedures

\begin{tabular}{|c|c|c|c|}
\hline $\begin{array}{l}\text { First author [ref.], } \\
\text { year }\end{array}$ & Publication type & Stapling device used & Summary and outcome \\
\hline $\begin{array}{l}\text { Molloy [12] } \\
2000\end{array}$ & case report & PPH03 & $\begin{array}{l}\text { Pneumoretroperitoneum and pelvic sepsis with an intact staple line after stapled } \\
\text { hemorrhoidectomy. Laparotomy and fecal diversion. Survived. }\end{array}$ \\
\hline $\begin{array}{l}\text { Bönner [13], } \\
2001\end{array}$ & case report & PPH03 & $\begin{array}{l}\text { Sepsis, staple-line dehiscence, and Fournier gangrene after stapled } \\
\text { hemorrhoidectomy. Fecal diversion and wide perineal and perianal excision. } \\
\text { Died. }\end{array}$ \\
\hline $\begin{array}{l}\text { Maw [14] } \\
2002\end{array}$ & case report & PPH03 & $\begin{array}{l}\text { Retroperitoneal sepsis with intact staple line after stapled hemorrhoidectomy. } \\
\text { Conservative medical treatment. Survived. }\end{array}$ \\
\hline $\begin{array}{l}\text { Ripetti [4], } \\
2002\end{array}$ & case report & PPH03 & $\begin{array}{l}\text { Pneumoretroperitoneum and pneumomediastinum after stapled } \\
\text { hemorrhoidectomy. Fecal diversion. Survived. }\end{array}$ \\
\hline $\begin{array}{l}\text { Delgadillo [7], } \\
2007\end{array}$ & case report & PPH03 & $\begin{array}{l}\text { Pneumoretroperitoneum after stapled hemorrhoidectomy. Intact staple line. } \\
\text { Conservative medical treatment. Survived. }\end{array}$ \\
\hline $\begin{array}{l}\text { Filingeri [15], } \\
2005\end{array}$ & case report & PPH03 & $\begin{array}{l}\text { Pneumoretroperitoneum and pneumomediastinum with staple line dehiscence } \\
\text { after stapled hemorrhoidectomy. Suturing of the staple line followed. Survived. }\end{array}$ \\
\hline $\begin{array}{l}\text { Schulte }[8] \text {, } \\
2008\end{array}$ & $\begin{array}{l}\text { case report, } \\
\text { letter to the editor }\end{array}$ & Contour Transtar ${ }^{\mathrm{TM}}$ & $\begin{array}{l}\text { Pneumoretroperitoneum and pneumomediastinum after the STARR procedure } \\
\text { for obstructed defecation syndrome with the Contour Transtar stapler. } \\
\text { Conservative medical treatment. Survived. }\end{array}$ \\
\hline $\begin{array}{l}\text { Gagliardi [3], } \\
2008\end{array}$ & $\begin{array}{l}\text { case series, } \\
\text { retrospective analysis }\end{array}$ & $\begin{array}{l}\text { (1) PPH01 } \\
\text { (2) } \mathrm{PPH} 01\end{array}$ & $\begin{array}{l}\text { (1) Pneumoretrorperitoneum with intact staple line after the STARR procedure } \\
\text { for obstructed defecation. Conservative medical treatment. Survived. } \\
\text { (2) Pneumoretroperitoneum with necrotizing pelvic fasciitis und necrosis of the } \\
\text { rectum and uterus. A Hartmann procedure followed. Died. }\end{array}$ \\
\hline $\begin{array}{l}\text { Naldini }[9], \\
2011\end{array}$ & case series & PPH01 & $\begin{array}{l}\text { Pneumoretroperitoneum with perineal sepsis. Hysterectomy and oophorectomy } \\
\text { followed. Died. }\end{array}$ \\
\hline
\end{tabular}

The WBC count and CRP normalized over the following 6 days. No fever was recorded. There was no abdominal discomfort or tenderness. The patient had normal bowel movements. She was discharged on day 10 after the initial surgery. Specimen pathology revealed no specificities and no presence of peritoneal tissue.

At follow-up nearly 4 months after surgery, the patient reported normal and regular passage of stools with no need for laxatives. The rectal examination revealed no signs of a rectocele or intussusception.

\section{Discussion}

The efficacy and safety of the STARR procedure using the Contour Transtar curved cutter stapler to treat ODS in the presence of a rectocele and/or intussusception have been supported by several prospective trials, including randomized trials and meta-analyses $[1,5]$. The randomized controlled trials reported in these meta-analyses did not find significant differences regarding the complication rates when the Contour Transtar was compared to STARR performed with circular staplers like PPH01 (Ethicon Endo-Surgery).

The patient we present here had undergone a transvaginal correction of her rectocele and cystocele 1 year prior to the STARR procedure to treat her worsening ODS. We could not identify clinical trials in the literature directly comparing the STARR procedure with a poste- rior colporrhaphy. There is only one publication that tries to compare the pros and cons of both approaches in terms of benefits and complications according to the available literature [6]. It has been suggested that the transvaginal approach offers better anatomical results, but that the transanal approach achieves better rectal function. However, in our opinion, this statement remains eminencebased when one considers the obvious lack of evidence. Furthermore, we have not been able to identify a similar reported case in the literature where a STARR procedure was performed in a patient who had previously undergone a posterior colporrhaphy.

Pneumoretroperitoneum after transanal stapling procedures, performed for treating hemorrhoidal prolapse or ODS, has been described in several publications [3]. In some case reports, the condition was described as oligosymptomatic with no evidence of staple-line defects, and was treated conservatively with antibiotics $[7,8]$. More severe cases have been described in the literature, ranging from rectal perforation [4] to fatal necrotizing pelvic fasciitis $[3,9]$. The management of these complications ranged from conservative treatment with antibiotics to laparotomy and fecal diversion (Table 1).

In our patient, the pelvic-floor MDT at our institute was reluctant to approve a surgical approach, either transanal or laparoscopic, due to the expected presence of scarring in the rectovaginal septum from previous posterior 
colporrhaphy. This ultimately led to a postponement of the indicated STARR procedure for a year, during which all conservative measures of treatment were exhausted. Laparoscopy, synchronous to the STARR procedure, was not indicated due to the absence of a coexisting enterocele.

There have been suggestions in the literature to perform stapled transanal rectal resections under laparoscopic surveillance in the presence of a coexisting enterocele to avoid small bowel entrapment in the staple line [10]. One retrospective study suggested that a concomitant enterocele was not associated with an increased risk of inadvertent entrapment of the small bowel in the staple line if the enterocele was only visible during the straining phase of a defecography [11]. This same study revealed, however, that $60 \%$ of the resected specimens contained peritoneal tissue, which indicated capturing of the peritoneal cavity with the stapling device. The authors thus recommended performing a synchronous laparoscopy during a STARR procedure only when there is a stable enterocele.

A concomitant enterocele was ruled out in our case via pelvicography and MRI defecography. Furthermore, specimen pathology did not reveal any specificities or the presence of peritoneal tissue in the staple line. Even though we were not able to confirm a dehiscence or indeed any defect in the anastomosis, we suspect that the presumed scarring at the level of the rectovaginal septum might have contributed to a suboptimal closure of the staple line introduced by the Contour Transtar ${ }^{\mathrm{TM}}$, which resulted in a pneumoretroperitoneum in terms of air infiltration or seepage of bacteria through the staple line.

\section{Conclusion}

Even though the STARR procedure using the Contour Transtar curved cutter stapler is considered safe and effective for treating ODS, serious complications have to be considered and expected, particularly when the procedure is performed at a potentially scarred location following previous surgery. Furthermore, the fact that the pelvic-floor MDT team anticipated complications in this particular case beforehand highlights the importance of an interdisciplinary approach for management.

\section{Statement of Ethics}

Our case report was approved by the Ethics Committee of the St. Marienkrankenhaus Siegen. The patient gave written informed consent to publish this case report with the accompanying data and images.

\section{Conflict of Interest Statement}

The authors have no conflicts of interest to declare.

\section{Funding Sources}

The authors did not receive any funding to publish this work.

\section{Author Contributions}

I.D. treated the patient, collected the follow-up data, and designed, wrote, and revised the manuscript. B.M. treated the patient and revised the manuscript. S.D.-D. treated the patient and revised the manuscript. F.W. critically revised the report for intellectual input and gave final approval of the version to be published.

\section{References}

1 Isbert C. [Transtar ${ }^{\mathrm{TM}}$ operation for rectocele and obstructed defecation syndrome]. Chirurg. 2016 Nov;87(11):924-32.

2 Pescatori M, Gagliardi G. Postoperative complications after procedure for prolapsed hemorrhoids (PPH) and stapled transanal rectal resection (STARR) procedures. Tech Coloproctol. 2008 Mar;12(1):7-19.

3 Gagliardi G, Pescatori M, Altomare DF, Binda GA, Bottini C, Dodi G, et al.; Italian Society of Colo-Rectal Surgery (SICCR). Results, outcome predictors, and complications after stapled transanal rectal resection for obstructed defecation. Dis Colon Rectum. 2008 Feb;51(2): 186-95

4 Ripetti V, Caricato M, Arullani A. Rectal perforation, retropneumoperitoneum, and pneumomediastinum after stapling procedure for prolapsed hemorrhoids: report of a case and subsequent considerations. Dis Colon Rectum. 2002 Feb;45(2):268-70.

5 Mercer-Jones M, Grossi U, Pares D, Vollebregt PF, Mason J, Knowles CH; NIHR CapaCiTY working group; Pelvic floor Society. Surgery for constipation: systematic review and practice recommendations: Results III: Rectal wall exci- sional procedures (Rectal Excision). Colorectal Dis. 2017 Sep;19(Suppl 3):49-72.

6 Leanza V, Intagliata E, Leanza G, Cannizzaro MA, Zanghì G, Vecchio R. Surgical repair of rectocele. Comparison of transvaginal and transanal approach and personal technique. G Chir. 2013 Nov-Dec;34(11-12): 332-6.

7 Delgadillo X. Severe complications after stapled hemorrhoidectomy: case report and review of literature. Posters. Colorectal Disease. 2007; 9(s3):13-60.

8 Schulte T, Bokelmann F, Jongen J, Peleikis HG, Fändrich F, Kahlke V. Mediastinal and retro-/ intraperitoneal emphysema after stapled transanal rectal resection (STARR-operation) using the Contour Transtar stapler in obstructive defecation syndrome. Int J Colorectal Dis. 2008 Oct;23(10):1019-20.

9 Naldini G. Serious unconventional complications of surgery with stapler for haemorrhoidal prolapse and obstructed defaecation because of rectocoele and rectal intussusception. Colorectal Dis. 2011 Mar;13(3):323-7.

10 Petersen S, Hellmich G, Schuster A, Lehmann D, Albert W, Ludwig K. Stapled transanal rectal resection under laparoscopic surveillance for rectocele and concomitant enterocele. Dis Colon Rectum. 2006 May;49(5):685-9.

11 Reibetanz J, Boenicke L, Kim M, Germer CT, Isbert C. Enterocele is not a contraindication to stapled transanal surgery for outlet obstruction: an analysis of 170 patients. Colorectal Dis. 2011 Jun;13(6):e131-6.

12 Molloy RG, Kingsmore D. Life threatening pelvic sepsis after stapled haemorrhoidectomy. Lancet. 2000 Mar;355(9206):810.

13 Bönner C, Prohm P, Störkel S. [Fournier gangrene as a rare complication after stapler hemorrhoidectomy. Case report and review of the literature]. Chirurg. $2001 \mathrm{Dec} ; 72(12)$ : 1464-6.

14 Maw A, Eu KW, Seow-Choen F. Retroperitoneal sepsis complicating stapled hemorrhoidectomy: report of a case and review of the literature. Dis Colon Rectum. 2002 Jun;45(6): 826-8.

15 Filingeri V, Gravante G. The last images. Pneumoretroperitoneum, pneumomediastinum and subcutaneous emphysema of the neck after stapled hemorrhoidopexy. Tech Coloproctol. 2005 Apr;9(1):86. 